\title{
UM BRINDE AO DIDEROT: CULTURA, IMAGINÁRIO URBANO E PUBLICIDADES DE CERVEJA
}

\author{
MARINA FRID ${ }^{1}$ \\ WILLIAM CORBO ${ }^{2}$
}

\begin{abstract}
RESUMO
Este artigo analisa publicidades de cerveja como sistemas de classificação que aproximam e distanciam bens e pessoas, delimitam espaços sociais e produzem significados. Para tanto, examina os anúncios de duas marcas com perspectivas distintas: a Antarctica e a Heineken. Com atuação no mercado nacional, sobretudo no Rio de Janeiro, a Antarctica se apropria de elementos da cultura brasileira e do imaginário "carioca" para dialogar com um público "local". Por outro lado, a Heineken apresenta um universo impessoal e cosmopolita para circular em diferentes mercados e atingir um público "global". 0 estudo comparativo desses dois casos demostra como a publicidade constrói representações do consumo de cerveja através de vinculações da bebida com certos temas, espaços, experiências, objetos, isto é, "unidades Diderot" (McCracken, 2003).
\end{abstract}

\author{
PALAVRAS-CHAVE \\ Antropologia do Consumo; Narrativa Publicitária; Sistemas Simbólicos.
}

\section{HERE'S TO DIDEROT: CULTURE, URBAN IMAGINARY, AND BEER ADVERTISING}

\begin{abstract}
This paper analyzes beer advertising as classification systems that connect and dissociate goods and people, delineate social spaces, and produce meanings. Therefore, this work examines ads for two brands that explore distinct perspectives: Antarctica and Heineken. Focused on the consumer market of Brazil, especially Rio de Janeiro, Antarctica incorporates elements of Brazilian culture and the "carioca" imagination to communicate with a "local" audience. On the other hand, Heineken presents an impersonal and cosmopolitan universe to circulate in different markets and reach a "global" audience. The comparative study of those two cases demonstrates how advertising constructs representations of beer consumption through linking the beverage to certain themes, spaces, experiences, objects, that is, "Diderot unities" (McCracken, 2003).
\end{abstract}

\section{KEYWORDS}

Anthropology of Consumption; Advertising Narrative; Symbolic Systems.

\footnotetext{
${ }^{1}$ Pesquisadora de pós-doutorado (PDR Nota 10 FAPERJ) no Programa de Pós-graduação em Comunicação e Cultura da UFRJ. Doutora e mestre em Comunicação Social pela PUC-Rio.

2 Professor Adjunto do Departamento de Antropologia Cultural do Instituto de Filosofia e Ciências Sociais da UFRJ. Doutor e mestre em Comunicação Social pela PUC-Rio.
} 


\title{
UN TOAST À DIDEROT: LA CULTURE, L'IMAGINAIRE URBAIN ET LA PUBLICITÉ DE LA BIÈRE
}

\begin{abstract}
RESUMEN
Este artículo analiza publicidades de cervezas como sistemas de clasificación que aproximan y distancian bienes y personas, delimitan espacios sociales y producen significados. Con esta finalidad, examina los anuncios de dos marcas con perspectivas distintas: Antarctica e Heineken. Con la actuación en el mercado de Brasil, especialmente en Río de Janeiro, Antarctica se apropria de elementos de la cultura brasileña y del imaginario "carioca" para dialogar con un público "local". Por otro lado, Heineken presenta un universo impersonal y cosmopolita para circular en diferentes contextos urbanos y alcanzar un público "global". El estudio comparativo de estos dos casos revela como la publicidad construye representaciones del consumo de cerveza a través de vinculaciones de la bebida con ciertos temas, espacios, experiencias, objetos, esto es, "unidades Diderot" (McCracken, 2003).
\end{abstract}

\author{
PALABRAS CLAVE \\ Antropología del Consumo; Narrativa Publicitaria; Sistemas Simbólicos.
}

\section{UN BRINDIS AL DIDEROT: CULTURA, IMAGINARIO URBANO Y PUBLICIDADES DE CERVEZA}

\begin{abstract}
RÉSUMÉ
Cet article analyse les publicités sur la bière en tant que systèmes de classification permettant d'approcher et de distancer les biens et les personnes, de délimiter les espaces sociaux et de produire des significations. Pour ce faire, l'article examine les annonces publicitaires de deux marques aux perspectives différentes: Antarctica et Heineken. Avec les opérations au le marché du Brésil, en particulier de Rio de Janeiro, l'Antarctica s'approprie des éléments de la culture brésilienne et l'imaginaire "carioca" pour dialoguer avec un public "local". D'autre part, Heineken présente un univers impersonnel et cosmopolite pour circuler sur les différents marchés et d'atteindre un public "global". L'étude comparative de ces deux cas montre comment la publicité construit des représentations de la consommation de bière à travers des association de la boisson avec certains thèmes, espaces, expériences, objets, c'est-à-dire des “unités Diderot" (McCracken, 2003).
\end{abstract}

\section{MOTS-CLÉS}

Anthropologie de la Consommation; Récit Publicitaire; Systèmes Symboliques. 


\section{NTRODUÇÃO}

O objetivo deste trabalho é investigar a gramática que rege as relações dos bens entre si e destes com pessoas, lugares e situações, especialmente nas narrativas publicitárias de cervejas. A proposta é analisar e comparar representações do consumo de cerveja construídas a partir de duas perspectivas distintas. Por um lado, os anúncios da marca líder de vendas no Rio de Janeiro, a Antarctica, concebidos em diálogo com a cultura brasileira e o imaginário carioca para um público "local". Por outro, as campanhas publicitárias da marca holandesa Heineken, que acionam certas imagens para atingir um ideal de público "global". A análise comparativa dessas duas perspectivas busca demonstrar como as publicidades das duas marcas atribuem diferentes significados a um mesmo tipo de produto através das conexões que estabelecem entre as cervejas e certos objetos, temas, sensações e ambientes. Também pode apontar para afinidades e discrepâncias nas concepções sobre o consumo de cerveja em contextos urbanos diversos, contribuindo para estudos sobre o lugar da publicidade no sistema capitalista.

A escolha da Antarctica nesta pesquisa se deve à sua sólida presença no Brasil e sua relevância no mercado de cervejas do Rio de Janeiro. Para integrar imagens e práticas características da cidade, a Antarctica explora associações com o samba, o boteco, a praia, o bom humor, o improviso e a beleza feminina. É através da constante interação com as noções de "jeitinho" e "malandragem" que o discurso publicitário estabelece a Antarctica como a cerveja que traduz brasilidade e o "estilo carioca". No caso da Heineken, a escolha acontece pela força da marca no mercado internacional e por sua entrada recente no Brasil, posicionando-se no segmento premium ${ }^{3}$. Sétima cerveja mais vendida do mundo ${ }^{4}$ a comunicação da Heineken alude ao conceito de cosmopolita (CALHOUN, 2008) e se sustenta em imagens associadas à globalização e às grandes cidades. Conecta-se com temas como multiculturalismo, cinema e sustentabilidade. Nesse sentido, a narrativa publicitária associa a Heineken com debates internacionalizados e à própria comunicação de massa na construção de uma marca de alcance global.

A análise desses dois contextos, anúncios feitos no/para o Brasil da Antarctica e anúncios de campanhas mundiais da Heineken, atende a dois objetivos inter-relacionados. Primeiro, demonstrar como opera o chamado "efeito Diderot" (MCCRACKEN, 2003) nas publicidades de cervejas. Segundo, indicar algumas semelhanças e diferenças entre representações do consumo da bebida no Brasil e aquelas concebidas por campanhas de marketing globais. Antes de apresentar as análises dos anúncios da Antarctica e da Heineken,

\footnotetext{
${ }^{3}$ Conforme site da Heineken Brasil: www.heinekenbrasil.com.br. Acesso em 02/02/17.

4 Conforme matéria "As 10 marcas de cerveja mais vendidas do mundo" da Exame: http://exame.abril.com.br/. Publicada em 12/05/16. Acesso em 02/02/17.
} 
cabe a revisão de algumas abordagens do consumo e da publicidade como sistemas que sustentam e traduzem significados culturais.

\section{"EFEITO DIDEROT" E NARRATIVAS dOS BENS}

Estudos que entendem o consumo como sistema simbólico apontam para o caráter complementar e comunicacional dos bens (DOUGLAS; ISHERWOOD, 2004; MCCRACKEN, 2003; ROCHA, 1985). McCracken (2003) denomina os padrões de complementariedade entre objetos de "unidades Diderot", homenagem a um ensaio do filósofo francês Denis Diderot (1772). Ao ganhar um elegante robe escarlate, Diderot percebe que o presente desencadeou um processo gradativo de transformação de todo seu quarto. Móveis, roupas e ornamentos, antes harmônicos, de repente pareciam muito modestos, gastos e velhos diante da beleza da nova peça. Consternado, o filósofo observou que a vestimenta, demasiadamente sofisticada, destoava dos demais elementos de seus aposentos e perturbava a coerência do conjunto original. O robe escarlate não combinava com os demais itens do quarto e, para mantê-lo, Diderot se viu forçado a realizar trocas sucessivas de outros objetos até recuperar o estado de equilíbrio.

Essa força conciliadora de produtos e serviços, o chamado "efeito Diderot" (MCCRACKEN, 2003), pode levar a dois extremos em termos de atividades de consumo. Como no exemplo do quarto do filósofo, o bem anômalo pode gerar uma ampla transformação do universo de bens anteriormente possuídos. Por outro lado, pode ser rejeitado pelo indivíduo mais conservador, que consegue identificar e repelir elementos potencialmente inadequados para garantir a coerência do padrão de objetos adquiridos (ROCHA; FRID; CORBO, 2016). O "efeito Diderot" é a exigência de complementariedade dos bens, que só faz sentido quando participa de um conjunto. Para McCracken (2003), consumidores compreendem o significado de um bem através da redundância gerada pela junção deste com outros bens que partilham da mesma significação. Ou seja, a combinação de bens pressupõe uma certa coerência entre os significados culturais de cada um deles.

A ideia de redundância talvez não seja suficientemente clara, pois os significados das coisas emergem pelo encaixe de umas com as outras e não apenas pela repetição ou excesso. Arqueólogos em geral recuperam informações de culturas ancestrais quando conseguem estabelecer conexões entre vestígios escavados. Uma vez agrupados, estes deixam de ser matéria e se tornam artefatos. Também a antropologia estuda cada grupo social como uma totalidade e os mediadores nas interações humanas como signos e símbolos (LÉVI-STRAUSS, 2013 [1960]; RODRIGUES, 2003). Por isso, os bens de consumo, como elementos que integram uma dada cultura, são melhor apreendidos como parte de um 
conjunto mais amplo de objetos, regras, práticas, técnicas e relacionamentos (DOUGLAS; ISHERWOOD, 2004).

Evidentemente, arranjos de seres e coisas podem variar consideravelmente entre as diversas tradições culturais. Não por acaso experiências em viagens, mesmo para lugares que não são tidos como "exóticos", podem causar estranhamento. Turistas brasileiros no exterior encontram coisas familiares usadas de formas diferentes (por exemplo, feijão cozido na refeição matinal dos britânicos); palavras semelhantes atribuídas a coisas distintas ("futebol" nos EUA, pedir uma "limonada" e receber um refrigerante sabor limão na Inglaterra); traduções que não fazem sentido ("jantar" de Ação de Graças às 15 horas nos EUA), além de costumes e símbolos que, à primeira vista, parecem incompreensíveis, como celebrar o "Dia da Panqueca" na terça-feira de Carnaval e manter uma família real sem poderes legislativos e executivo no Reino Unido.

Rocha (1985) entende o consumo e as narrativas publicitárias que o sustentam como sistemas de classificação análogos ao chamado totemismo, ou pensamento mágico, estudado em sociedades tribais (LÉVI-STRAUSS, 2011 [1962]). Como uma espécie de "operador totêmico", a publicidade efetua a passagem entre as duas esferas fundamentais do capitalismo moderno, a produção e o consumo. Coisas feitas por processos impessoais, massivos, uniformes e mecanizados no domínio "não-humano" da produção (MARX, 2008 [1867]) adquirem significados e se tornam inteligíveis no domínio "humano" do consumo através de anúncios, logomarcas, embalagens, entre outras estratégias de comunicação. A publicidade reveste a mercadoria de propriedades simbólicas, apaga sua história social e transforma o que é originalmente indistinto e sem sentido em algo singular e integrado ao universo social. Assim, cria relações de semelhança e diferença entre os bens e destes com pessoas (ROCHA, 1985).

Portanto, a harmonia entre os objetos observada por McCracken (2003) está fundamentada na lógica do pensamento mágico, isto é, na classificação por pares de oposição que converte produção em consumo (ROCHA, 1985). Evidentemente, as modernas técnicas publicitárias, do marketing e do design eram incipientes quando Diderot escreveu seu ensaio e sua percepção sobre a inadequação do robe escarlate provavelmente adveio de inferências sobre a origem do presente, o tipo e cor do tecido, as ocasiões, espaços e pessoas usualmente ligadas ao traje, julgamentos estéticos, entre outros critérios. De todo modo, a classificação de tipo totêmico se evidencia no imperativo de conciliação dos bens, complementariedade sem a qual nada pode significar (ROCHA; FRID; CORBO, 2016).

Já no capitalismo moderno, a publicidade se torna um dos recursos fundamentais para dar sentido à massa de objetos oferecidos pela produção industrial. As narrativas publicitárias, junto com outras ações de comunicação e marketing, associam bens a lugares, pessoas, emoções e valores; inserem produtos e serviços no imaginário do consumo por 
meio de analogias, como se correspondessem a ideias já existentes na cultura: amor, verão, férias, família, amizade, entre outras. Nas seções a seguir, o artigo analisa como anúncios da Antarctica e da Heineken revestem cervejas de significados e as transformam em bens de consumo interligados a diferentes experiências urbanas.

\section{ANTARCTICA, CULTURA BRASILEIRA E IMAGINÁRIO CARIOCA}

A Antarctica foi fundada em 1885, inicialmente como uma fábrica de gelo e produtos alimentícios localizada no bairro de Água Branca, na cidade de São Paulo, Brasil. Em 1889, a empresa inicia a produção de cervejas e tem seu primeiro anúncio publicado no jornal "A Província de São Paulo" - atual "Estado de S. Paulo". Em 1891, A Antarctica tornou-se sociedade anônima e entre os acionistas estavam dois empresários imigrantes naturalizados brasileiros: o alemão Antônio Zerenner e o dinamarquês Adam Ditrik. Proprietários da casa de importação Zerenner, Bullow e Cia., responsável pela entrada de cervejas alemães no Brasil durante a segunda metade do século XIX, investiram em máquinas necessárias para qualificar a produção da Antarctica. Se no final da década de 1890 a companhia produzia 42 mil litros de cerveja por dia, em 1960 sua capacidade de produção de cervejas e refrigerantes atingia 3,9 milhões de hectolitros por ano. Em 1999, foi concretizada a união da Antarctica e da Brahma para a criação da Ambev, que, em 2004, se juntou à belga Interbrew e deu origem à Inbev. Mais adiante, em 2008, a multinacional comprou a Anheuser-Busch, a maior cervejaria dos Estados Unidos, e formou a $A B$ Inbev, líder no mercado mundial de cerveja. Apesar de fazer parte do maior conglomerado do segmento, presente em centenas de países, a Antarctica se posiciona como uma marca local e concentra sua atuação no Brasil, especialmente no Rio de Janeiro.

Ao longo dos anos, a publicidade da marca passou a articular a Antarctica com elementos distintivos do Brasil e, sobretudo, com o ideal do "tipicamente carioca". Os comerciais da marca aqui examinados, parte de campanhas lançadas de 2004 a 2016, estabelecem uma estreita conexão entre a cerveja Antarctica, a brasilidade e o Rio de Janeiro pela apropriação de símbolos - como a morena, a mulata passista e o malandro -, de rituais especiais e cotidianos - como o carnaval de rua, o futebol, a roda de samba e a "cervejinha" com os amigos - e de espaços de convivência - como a laje no morro, o bar e a praia. Exploram comportamentos como o "jeitinho brasileiro", o apreço pela abundância, a alegria e a cordialidade, bem como a importância da amizade, da intimidade e da informalidade nas relações sociais. A análise dos anúncios da Antarctica mostra, portanto, como as narrativas sobre a marca recorrem a um repertório de valores, práticas, lugares, sons e imagens que guardam uma profunda identificação com o Brasil, tal como argumentam diferentes estudos 
sobre a cultura e a história do país (FREYRE, 1975 [1933]; 1986; HOLANDA, 1995 [1936]; 2000 [1959]; DAMATTA, 1979; BARBOSA, 1992; SCHWARCZ, 1994; VIANNA, 1995).

Em 2006, a Antarctica lançou a campanha do "Bar da BOA" (Bebedores Oficiais de Antarctica), o melhor lugar para encontrar amigos e beber cerveja. O primeiro filme da campanha apresenta o animado "Bar da BOA", a atriz Juliana Paes como proprietária, seus funcionários e a cerveja Antarctica. Destaca-se o trocadilho que o anúncio faz com o nome do "Bar da BOA", que pode ser aquele da Antarctica, a cerveja boa, e também o da atriz Juliana Paes, a mulher "boa" devido às formas do seu corpo, acentuadas pelo figurino, gestual e ângulos captados pelas imagens. Assim, a marca se alinha a uma estratégia recorrente nas publicidades de cervejas no Brasil, que vinculam a bebida às representações da beleza feminina.

O anúncio mostra um bar cheio e o nome "Bar da BOA" no letreiro. A letra "o" de BOA é substituída pelo logotipo da Antarctica. Em off, o locutor explica: "Este é o Bar da BOA". No meio do salão, repleto de clientes, uma mulher de blusa azul e saia curta branca desfila de maneira sensual em direção ao freezer de cervejas Antarctica. É Juliana Paes. "Рra você ter uma ideia, esta é a dona. Boa, toda boa", continua o locutor entusiasmado. Ela sorri para a câmera e mostra uma garrafa de Antarctica, dizendo: "Boa é essa aqui, ó". Em seguida, conhecemos os funcionários do bar, uma mulher e um homem que trabalham atrás do balcão de camisa e avental, além de duas garçonetes, que servem Antarctica vestindo blusas decotadas e saias curtas. Uma garrafa e um copo da cerveja aparecem no centro da tela enquanto o locutor informa: "Esta é a cerveja que é servida lá, muito boa". Grupos de amigos conversam animadamente enquanto bebem cerveja. Mas o clima de repente muda quando uma garrafa esvazia. Rapidamente, a dona do bar, com dois copos cheios de Antarctica, caminha na direção dos clientes e fala: “Calma, gente. Tem pra todo mundo!". Todos comemoram e o anúncio termina com a imagem de um copo cheio de cerveja no foco, enquanto o locutor diz: "Boa, só se for Antarctica".

Em 30 segundos, o anúncio sintetiza diversos temas que atravessam a cultura brasileira, como a abundância do "paraíso terrestre" (HOLANDA, 2000 [1959]), onde não falta cerveja Antarctica, e a "consagração da morenidade" (FREYRE, 1986) com o destaque conferido ao corpo e à sensualidade da personagem de Juliana Paes. O próprio duplo sentido do adjetivo "boa", que pode se referir tanto à cerveja quanto à dona do bar, revela o humor malicioso do malandro (DAMATTA, 1979; SCHWARCZ, 1994). Em especial, o comercial enfatiza o compadrio e a proximidade dos grupos de amigos, que se sentem à vontade no "Bar da BOA", como se estivessem em "casa", e destes clientes com os funcionários e a proprietária do local, o que remete aos ensinamentos de Holanda (1995), DaMatta (1979) e Barbosa (1992) sobre a tendência dos brasileiros de tornarem íntimas as relações mesmo em ambientes e situações supostamente impessoais. 
Em 2010, a Antarctica se inspirou nos rituais de grupos de amigos que se reúnem religiosamente no mesmo bar, sentam sempre na mesma mesa e falam sobre os mesmos assuntos para elaborar a assinatura "Boa é Antarctica. A cerveja da Diretoria", com peças criadas pela agência AlmapBBDO. Novamente, a cerveja produzida em um ambiente industrial e servida na esfera pública da "rua" (DAMATTA, 1979) torna-se pessoal e familiar ao ser repassada pelo valor da amizade.

O comercial "Privilégios", que apresenta o conceito de "diretoria" da Antarctica, contou com o cantor, ator e humorista Sérgio Loroza. Ele aparece atrás do balcão do bar onde estão uma garrafa de Antarctica e um copo cheio de cerveja - e diz: "Diretoria é uma turma gente boa, que sabe aproveitar o melhor do bar". Três homens brindam em uma mesa próxima à escada, quando outro cliente se aproxima do grupo e pergunta por que escolheram sentar ali. Nesse momento, uma mulher de vestido sobe a escada e todos olham para cima, tentando espiar seu corpo por baixo da roupa. Na cena seguinte, os quatro homens se sentam em uma mesa perto da geladeira cheia de cervejas Antarctica, pois, como indica o narrador, "O lugar mais refrescante do bar a Diretoria sabe onde é". O garçom abre a geladeira, serve quatro cervejas e pergunta se a temperatura está boa; em clima de descontração, os amigos respondem de maneira afirmativa. Com um abridor especial, o garçom abre as quatro garrafas ao mesmo tempo e o narrador segue: "Garçom que abre a cerveja mais rápido a Diretoria sabe qual é". Loroza reaparece atrás do balcão, coloca um crachá no pescoço da garrafa de Antarctica e explica: "Diretoria é isso, amigos em torno de uma BOA gelada". O narrador finaliza com o slogan "BOA é Antarctica. A cerveja da Diretoria". Os quatro amigos novamente aparecem sentados na mesa embaixo da escada, agora observando a mesma mulher descer os degraus. Eles brindam para comemorar "a BOA".

Em 2013, a marca homenageou o Rio de Janeiro na campanha "Brinde ao Rio", que contou com a participação de grandes nomes da música brasileira, como Arlindo Cruz, Marcelo D2, Mart'nália e Mumuzinho. Assinado pela AlmapBBDO, o anúncio principal da campanha brinda às paisagens do Rio, ao povo carioca, aos amores, à cerveja, ao carnaval e, finalmente, ao samba. As imagens mostram o calçadão na praia, um casal apaixonado, mulheres de biquíni e minissaia, um palhaço no bloco de carnaval, um bar, uma roda de samba, um malandro todo de branco e chapéu panamá, pessoas que dançam ao som do batuque e o famoso morro Pão de Açúcar. Um narrador em off diz: "Às alvoradas, aos amores, ao jeito dela andar. À boa gelada em cima da mesa, aos malandros, à velha guarda. A todas as festas, rodas, feijoadas, ao morro, ao povo, ao Rio. A tudo que um dia virou ou vai virar samba, um brinde da Diretoria. Antarctica, um brinde às coisas boas do Rio".

Em 2016, uma nova campanha da Antarctica homenageou os 100 anos do samba. No comercial "Antarctica: Vice e Versa \#batuquedaBOA", novamente aparecem as paisagens do Rio, a descontração, a informalidade, o futebol, o convívio nos bares, nas praias e nos morros. 
Em off, o narrador diz: "O samba só é o samba por causa do carioca, pela capacidade que ele tem de enxergar alegria até na tristeza, pela leveza que ele traz pra qualquer situação, pelo rebolado que só o carioca consegue ter, o jogo de cintura, e o talento de transformar o improviso em arte." Já o trecho seguinte explica como o samba influencia a postura, as atitudes e as emoções dos cariocas: "É o samba que ensina a transformar o improviso em arte, que dá pro carioca o rebolado, aquele jogo de cintura, que inspira a trazer leveza pra qualquer situação, e ensina a ver alegria até na tristeza." Finalmente, em uma roda de samba, o cantor Martinho da Vila resume: "É o seguinte, não tem mistério, o carioca fez o samba e o samba fez o carioca, numa boa." E o narrador encerra: "Uma homenagem aos 100 anos do samba de quem sempre esteve lá, numa boa".

Os tributos ao Rio de Janeiro e ao samba carioca evidenciam um aspecto crucial do imaginário do Brasil. Antiga capital federal e única metrópole nas Américas a ter assumido a condição atípica de sede de um império Europeu, o Rio de Janeiro historicamente ocupa o lugar de vitrine e principal referência do país para o mundo. A cidade e o ideal do "carioca", portanto, consolidam diversos traços da cultura brasileira e têm suas especificidades generalizadas para todo país. Em outras palavras, o Rio de Janeiro consiste em um símbolo do Brasil, amplamente explorado pela comunicação de massa dentro e fora país. Exemplos desse fenômeno são o personagem Zé Carioca, criado na década de 1940 pela Walt Disney (SCHWARCZ, 1994) e a adoção do samba como elemento da identidade nacional (VIANNA, 1995). Da mesma forma, as narrativas publicitárias da Antarctica abordam códigos, costumes e atividades ligadas ao Rio de Janeiro, mas que, até certo ponto, também fazem parte do repertório mais abrangente da cultura brasileira.

\section{A HEINEKEN E O CONSUMIDOR COSMOPOLITA}

A história da Heineken começa em 1864, quando Gerard Heineken comprou uma cervejaria em Amsterdã, na Holanda, então chamada Haystack. Passados mais de 150 anos, a sede da empresa permanece na cidade de origem, onde o museu Heineken Experience integra o roteiro básico de turistas do mundo inteiro, mas sua cerveja já se encontra em mais de 190 países. A internacionalização da empresa começou nas primeiras décadas do século XX em regiões da África e da Ásia. Aterrissou nos EUA em 1933 com o fim dos 13 anos de "lei seca", o banimento da produção, importação e circulação de bebidas alcóolicas no país. Em 1968, comprou a rival holandesa Amstel e o processo de expansão continuou com aquisições de participação majoritária no Grupo Dreher em 1974 e de diversas cervejarias do Leste Europeu e do Reino Unido nas décadas subsequentes. Em 2010, a Heineken adquiriu o segmento de cervejas do grupo mexicano FEMSA, que inclui as brasileiras Kaiser e Bavaria. Com isso, a Heineken estabeleceu sua presença no Brasil e entrou na disputa por espaço nas gôndolas de 
supermercados e nos cardápios de bares e restaurantes. Em 2017, a marca anunciou a compra da Brasil Kirin, um negócio que a transformará na segunda maior cervejaria do país.

A expansão da cerveja holandesa também tornou mais constante a disseminação de seus anúncios na mídia brasileira. Em 2011, logo após sua entrada no Brasil, a Heineken lançou uma campanha global pela agência Wieden+Kennedy com o slogan "Open your world" ${ }^{5}$. O primeiro filme publicitário, intitulado "The entrance", com versões para televisão e mídias digitais, trabalha a ideia de "homens lendários", que transitam com segurança em ambientes diversos pelo mundo e são capazes de reconhecer uma boa cerveja ${ }^{6}$. De fato, o consumidor de Heineken é classificado como cosmopolita (CALHOUN, 2008), o "cidadão do mundo", entendido na publicidade como um indivíduo que se sente confortável com a diferença e tem seu gosto moldado por experiências culturais diversas.

No comercial, um homem jovem faz uma entrada triunfante em uma grande festa. Passa pelo tapete vermelho saudando os seguranças na porta, despreocupado com os flashes de fotógrafos, e é recepcionado por um elegante senhor de smoking e sua esposa em traje de gala. Um garçom atencioso logo the oferece uma bebida, parece um Martini, mas ele estende a mão em direção a uma garrafa long neck verde da Heineken servida na bandeja seguinte. Não consegue, porém, alcançar a cerveja. É interrompido por uma fila de convidados ilustres, ávidos para cumprimenta-lo: um africano cerimonioso, uma elegante indiana acompanhada de um nobre e um oficial condecorado, com tapa-olho de pirata, a quem presenteia com um globo ocular. Apesar da formalidade da ocasião e das roupas, o homem tem uma atitude descontraída e animada. Atrai olhares de damas enfeitadas, brinca com o xerife, limpa habilmente o rosto da mulher que prova um canapé, joga basquete contra atletas engravatados e acerta a cesta. Quando chega ao salão principal, ganha um ovo Fabergé de um "poderoso chefão" e, em troca, faz surgir magicamente um passarinho. Em seguida, é desafiado por um lutador de kung Fu e ganha a disputa por uma cerveja Heineken, que ele graciosamente oferece ao adversário. Finalmente, o homem recebe uma flauta transversal, sobe ao palco com a banda "The asteroids galaxy tour" e ganha sua Heineken. Um plano geral da festa mostra todos os convidados dançando e o protagonista do anúncio no centro do palco, com a vocalista da banda ao seu lado, iluminado por um holofote. O efeito de transição para o último quadro é na forma de uma estrela que se fecha até surgir a logomarca da Heineken e o slogan "open your world" sobre um fundo verde.

Em suma, o anúncio mostra um homem confiante, que entra em uma festa repleta de pessoas importantes, de todas as partes do mundo, e domina a situação com suas habilidades cosmopolitas. É uma pessoa de "mente aberta", globetrotter, como sugere o

\footnotetext{
${ }^{5}$ Conforme matéria "'Open Your World' é o novo slogan da Heineken" do blog Elias Rodrigues https://eliasrodrigues.wordpress.com/. Publicada em 02/03/11. Acesso em 26/02/17.

${ }^{6}$ Conforme resumo no site da agência Wieden+Kennedy: www.wk.com. Acesso em 26/01/17.
} 
slogan "open your world". Fica claro o contraste entre esse filme e os anúncios da Antarctica examinados na seção anterior. Aqui a cerveja não ganha atributos de "gostosa" ou "gelada", não é associada ao verão, à sensualidade feminina e nem a relações pessoais entre amigos, casais ou parentes. A Heineken aparece, sobretudo, como uma bebida para homens confiantes e "descolados". Apesar dos personagens representarem diferentes profissões e culturas, o ambiente refinado da festa transmite mais exclusividade do que a ideia de popular. Basta notar que o evento acontece em espaço fechado, com seguranças e tapete vermelho estendido na entrada, além dos jornalistas que fotografam o protagonista como se fosse uma celebridade. O edifício histórico, repleto de arcos, tapetes, lustres de cristal, candelabros, portais e paredes de madeira, também remete à atmosfera glamorosa da "егa dourada" mencionada na música. Os figurinos de paletó e gravata, vestidos longos e joias brilhantes reiteram o requinte da festa. Nesse sentido, a cerveja equaliza pessoas de interesses e origens diversas, mas não atinge necessariamente diferentes faixas de renda. Além disso, a Heineken não aparece como uma bebida refrescante, gelada ou leve. De fato, o protagonista sequer toma um gole durante todo o comercial. Também não há relação entre a cerveja e a imagem da mulher. O anúncio estabelece associações entre as qualidades do protagonista e as da Heineken. Portanto, o homem é a parte sedutora que desperta a atenção feminina.

Em 2012, a Heineken iniciou uma parceria com a franquia do agente secreto 007 para sua campanha de marketing global. James Bond, interpretado pelo ator Daniel Craig, apareceu em comerciais da cerveja nas ocasiões dos lançamentos dos filmes Skyfall (RU/EUA, 2012) e Spectre (RU/EUA, 2015). Este acordo foi uma novidade tanto para o universo publicitário das cervejas quanto para os fãs do espião britânico, geralmente associado a Martinis, coquetéis e destilados. Mas a iniciativa do marketing da Heineken de se aliar à franquia 007 potencializou o conceito de "homens lendários". Novamente, o atributo de "cosmopolita" é a chave para classificar a cerveja e o seu consumidor, dessa vez com o suporte de um dos grandes heróis da cultura de massa. Nos dois comerciais da parceria, indivíduos desconhecidos acabam sendo perseguidos junto com James Bond e conseguem se desvencilhar dos vilões com muita habilidade. O primeiro se passa em um luxuoso trem no inverno russo, enquanto o segundo encena uma perseguição de lancha em um balneário europeu. Vale observar que long necks da Heineken aparecem na ação, mas a cerveja não é saboreada pelos protagonistas.

Em 2016, a empresa optou por mudar de agência e estratégia de comunicação. Deixou de lado o conceito de "consumidores lendários" para focar mais na própria cerveja. A presença global da Heineken continuou em primeiro plano, agora associada ao sabor e controle de qualidade da bebida, que permanece idêntica em todos os países onde é comercializada. O astro hollywoodiano Benicio del Toro é o protagonista dos novos 
comerciais. Nascido em Porto Rico, com cidadania nos Estados Unidos e na Espanha, ele venceu o Oscar de melhor ator coadjuvante em 2001 pelo filme Traffic (EUA/Alemanha, 2000). Com a escolha desse "garoto-propaganda", a categoria de cosmopolita permanece na campanha. O protagonista agora aparece em situações mais cotidianas, como em restaurantes, bares e até no Natal em família.

Um dos anúncios veiculados mundialmente, inclusive no Brasil, explora com humor a notoriedade internacional do ator e da Heineken, ambos conhecidos por toda parte, ainda que admiradores possam cometer eventuais equívocos. Nele Benicio del Toro está em um restaurante cheio, sentado à mesa com um grupo de pessoas. A câmera foca no ator e se aproxima enquanto ele fala: "A Heineken é servida em 192 países. É mundialmente famosa [Pausa], como eu.". Um casal de turistas avista o ator dentro do restaurante e bate entusiasmadamente na janela de vidro para chamar sua atenção. Isso acontece sempre", o ator comenta com um pouco de orgulho. Ele se vira para cumprimentar os fãs. Com a máquina presa em um selfie stick, o casal posa sorridente para uma foto com o astro e grita "Antonio Banderas!". Eles riem e pulam de alegria por terem conseguido um registro da celebridade. Afinal, "É o Antonio Banderas, o cara dos filmes!". O ator olha para a câmera visivelmente frustrado e uma legenda entre parênteses indica que "(Esse NÃO é o Antonio Banderas)". O filme termina com uma imagem de um copo e uma long neck da cerveja sobre o balcão de um bar acompanhados da frase "A única cerveja saboreada em 192 países". O voice-over final reproduz o slogan da nova campanha "There is more behind the star" ("Existe mais por trás da estrela"), um convite aos consumidores a conhecerem melhor a Heineken. Cabe mencionar o trocadilho com a palavra "estrela" no slogan: é uma referência ao ícone vermelho na logomarca da Heineken e ao ator hollywoodiano, Benicio del Toro.

Outro comercial da cerveja holandesa resulta de uma iniciativa de marketing da empresa no âmbito dos esportes. Desde 2005, a Heineken patrocina a Liga dos Campeões da UEFA, campeonato de futebol europeu acompanhado por mais de 4,2 bilhões de espectadores em todo mundo ${ }^{7}$. Em 2016, a agência Publicis Brasil desenvolveu uma ação especial para a final do torneio. Três homens - Getúlio, Rafael e Felipe - foram convidados a assistir a partida, que aconteceu no dia 28 de maio, em um evento da Heineken na cidade de São Paulo. Porém, o convite tinha uma condição: eles não poderiam levar e nem contar às suas namoradas sobre o evento. Ao contrário, deveriam presenteá-las com um fim de semana no spa (na verdade, cortesia da Heineken) como distração. No filme, intitulado "O cliché", os casais estão em um restaurante em um jantar a dois. As legendas na abertura explicam: "São Paulo, uma semana antes da final da UEFA Champions League... E se você tivesse a desculpa perfeita para assistir à final numa festa Heineken... Sem sua namorada?".

7 Conforme release da empresa, publicado em 13/10/15 no site http://www.theheinekencompany.com/. Acesso em 31/01/16. 
Os homens recebem um cardápio do garçom com uma mensagem semelhante e a solução: "Dê para sua mulher um fim de semana neste spa". Logo abaixo está colado um cartão de um "spa Handel". Aparentemente surpresos com a oportunidade, os três começam a elaborar seus discursos para oferecer o presente, dizendo coisas como "Amor, você sabe como te respeito, como te admiro", "você está muito, tipo, carregada", "acho que você precisa de um tempo pra você", "aproveitei a ocasião pra comprar um presente pra você". As mulheres reagem com um misto de alegria pelo gesto e frustração por estarem sendo "despachadas" por vários dias. Finalmente, os casais brindam com long necks da Heineken.

Nessa primeira parte do comercial, a Heineken não apenas é vinculada ao campeonato de futebol europeu, mas também a situações e ambientes, como grandes cidades, passeios noturnos, jantares em restaurantes e spas. Em seguida, o anúncio mostra o dia do jogo. Os três homens chegam juntos no evento da Heineken e se sentam em um local especialmente designado na frente de um telão. Eles recebem as boas-vindas com um vídeo que deseja: "Curtam a final assim como suas mulheres estão curtindo o spa". As três namoradas aparecem de roupão e com cabelos enrolados em toalhas. Elas falam sorridentes que estão "curtindo muito" todos os tratamentos, massagens e, sobretudo, "Milão!!!". Elas pulam, gritam e tiram os roupões, enquanto a cortina atrás delas cai revelando o estádio onde acontece a partida decisiva da Liga dos Campeões. Isto é, a Heineken não ofereceu para as mulheres um fim de semana no spa e sim uma viagem para o jogo. Enquanto elas celebram, os homens perplexos começam a rir e a esconder o rosto envergonhados. No vídeo aparece a pergunta: "Já pensou que ela pode gostar de futebol tanto quanto você?". O comercial encerra com mais uma surpresa para eles. Suas namoradas anunciam que a Heineken prometeu convites para os três casais participarem da final do campeonato na Europa em 2017.

O comercial foi todo filmado em português, mas legendado em inglês para transmissão internacional. Vale observar que, embora a narrativa envolva três casais de namorados, ideias de romantismo, sensualidade e intimidade estão quase ausentes. Não há contato físico, os casais são separados e a ação se baseia justamente no desconhecimento dos homens sobre as preferências de suas mulheres. Nesse sentido, o tom impessoal da publicidade da Heineken se mantém, algo que provavelmente facilita a circulação do anúncio em diferentes países.

\section{CONSIDERAÇÕES FINAIS}

O presente artigo examina anúncios da Antarctica e da Heineken para demonstrar como duas marcas de cerveja adotam perspectivas distintas e constroem significados diversos para um mesmo tipo de mercadoria através do diálogo com elementos já 
disponíveis em imaginários culturais. A análise verifica a articulação de certas "unidades Diderot" em um conjunto de anúncios das duas marcas, que vinculam a bebida a diferentes referências decifráveis por seus públicos. Por meio dessas associações, as narrativas publicitárias classificam a cerveja e seus consumidores de acordo com determinados bens, valores, situações e espaços sociais. Nesse sentido, a análise dos anúncios ajuda na compreensão de semelhanças e diferenças nas representações e práticas do consumo de cerveja em diferentes imaginários culturais. Por um lado, a brasileira Antarctica busca inspiração nos códigos do estilo "tipicamente carioca" e direciona sua comunicação para um público "local". Por outro, a Heineken articula a cerveja com elementos do ideal cosmopolita para alcançar uma plateia "global", dispersa nos mercados de centenas de países.

Para a Antarctica, a identificação com o Brasil e, sobretudo, com o Rio de Janeiro é a estratégia central de comunicação com seus consumidores. Seus anúncios incorporam e reificam elementos constitutivos da cultura brasileira e do imaginário carioca para sustentar a marca no mercado nacional. A associação com o samba, os bares, a praia, os corpos femininos, a morena, a descontração, a informalidade, a malandragem, a amizade e o jeitinho transforma a Antarctica em sinônimo de brasilidade. Assim, a publicidade integra a cerveja nos rituais cotidianos do consumidor nascido e criado no Brasil, ou que ao menos já é conhecedor da língua, hábitos, gostos e valores locais. Essas "unidades Diderot" possibilitam que a Antarctica se comunique com plateias possuidoras de um repertório de informações que as permite decodificar certas analogias. Mais do que dialogar com os consumidores do Rio de Janeiro, a marca aposta na generalização dos símbolos da cidade para alcançar diferentes praças no Brasil.

Por sua vez, a Heineken aposta na criação de um universo impessoal, pois sua ambição é o reconhecimento mundial da marca. A mesma cerveja, com o mesmo rótulo, precisa circular em mercados completamente distintos. Por isso seus anúncios tentam retratar festas que poderiam acontecer em qualquer lugar, recorrem a símbolos mundialmente difundidos pelo cinema e a eventos internacionalizados. A Heineken dialoga com um público multicultural, mas que, por outro lado, compartilha de um repertório comum aos indivíduos que participam mais intensamente do processo de globalização: que moram ou atuam em centros urbanos, de camadas econômicas média e alta, com certo tipo de educação, que têm acesso a produtos midiáticos difundidos pelo cinema, televisão e mídias digitais.

Nesse sentido, é significativa a opção da Heineken no Brasil de centrar seus anúncios em São Paulo, cidade mais ligada a valores, comportamentos e objetos da modernidade autonomia, pressa, anonimato, indústrias, máquinas, dinheiro (SIMMEL, 1969 [1903]; SENNETT, 1988) - e atividades de consumo associadas à globalização, como mídias, megaeventos e música pop (ROCHE, 2000; VERBOORD; BRANDELLERO, 2018). Enquanto o Rio de Janeiro simboliza o ser "brasileiro", São Paulo sintetiza diversos aspectos ligados ao 
ideal cosmopolita. Ao optarem por associações com certos elementos, as publicidades das marcas interpretam as noções de "local" e "global" e também acabam por reforçá-las.

A análise comparativa dos anúncios de Antarctica e Heineken evidencia como a publicidade atribui significados diversos a líquidos aparentemente iguais ao gerar combinações que partem de diferentes pontos de vista. Isto é, as representações publicitárias classificam as duas marcas de cerveja e seus respectivos consumidores por meio de categorias distintas. Um comercial de Antarctica da série "código de ética da diretoria", produzido em 2014 pela AlmapBBDO, comenta a diferença entre os consumidores da cerveja da marca e aqueles de outras bebidas alcóolicas. Três amigos conversam na praia quando avistam uma área "VIP" com DJ de música eletrônica, sofás, garçons, drinques em taças, garrafas de espumante e segurança para verificar a pulseira dos convidados. De fato, a festa exclusiva é justamente o tipo de ambiente retratado nos anúncios da Heineken, só que caricaturado e deslocado para as areias de uma praia carioca. Diante dela, os amigos rapidamente improvisam uma roda de samba, com um isopor repleto de latas de Antarctica no centro, acessível a todos que quisessem beber, batucar e dançar. Vale notar que os "VIPs" estão completamente vestidos de camisa polo, cinto, sapatos, relógio, etc., enquanto todos no samba estão com os corpos mais a mostra - descalços, de bermuda de praia, shorts ou biquíni. A roda de samba faz tanto sucesso que até os convidados da festa "VIP" querem tirar suas pulseiras e se juntar a ela. O anúncio termina com o código da "diretoria": "Na praia, todo mundo é igual". Nesse ideal de praia da Antarctica são excluídos os objetos e atitudes vinculados aos "VIPs".

Portanto, o exame comparativo dos comerciais de Antarctica e Heineken permite compreender como a publicidade confere sentidos às mercadorias e as encaixa em diferentes imaginários culturais. Principalmente, a análise do contraste entre os anúncios das marcas esclarece o chamado "efeito Diderot", que decorre da classificação de bens e pessoas na esfera do consumo. As publicidades das marcas se sustentam em duas categorias distintas - "brasileiro" e "cosmopolita" -, que desencadeiam diferentes arranjos combinatórios de comportamentos, emoções, sons, músicas, lugares e objetos. Um ponto em comum é que tanto Antarctica quanto Heineken tendem a associar o consumo de cerveja mais ao público masculino. Porém, para a primeira, a masculinidade envolve a parceria com os amigos e a contemplação da mulher, que é sedutora com seu corpo e charme. Já no universo impessoal da segunda, mesmo quando o anúncio encena sedução, a ênfase geralmente está no homem como a parte que atrai ou que tenta seduzir, e não na mulher. Sendo assim, na publicidade da Antarctica, a cerveja se transforma em elemento de comunhão, meio de criar e reforçar laços de amizade e intimidade. Diferentemente, nas representações da Heineken, o consumo da cerveja é uma realização do indivíduo, uma exaltação do "consumidor do mundo" e suas afinidades com pares espalhados em diversos centros urbanos. A análise comparativa dos 
anúncios de Antarctica e Heineken demonstra as relações entre bens e pessoas que se estabelecem nos imaginários culturais a partir de noções de brasilidade e cosmopolitismo.

\section{REFERÊNCIAS}

BARBOSA, L. 0 jeitinho brasileiro ou a arte de ser mais igual que os outros. Rio de janeiro: Campus, 1992.

DIDEROT, D. Regrets sur ma vieille robe de chambre, par M. Diderot, avis à ceux qui ont plus de goût que de fortune, 1772. Disponível em: ark:/12148/bpt6k1040210b. Acesso em: novembro de 2018.

CALHOUN, C. Cosmopolitanism in the modern social imaginary, Daedalus, v.137, n. 3, p. $105-114,2008$

DAMATTA, R. Carnavais, malandros e heróis. Rio de Janeiro: Zahar, 1979.

DOUGLAS, M; ISHERWOOD, B. 0 mundo dos bens: para uma antropologia do consumo. Rio de Janeiro: Editora da UFRJ, 2004.

FREYRE, G. Casa grande e senzala. Rio de Janeiro: José Olympio, 1975 [1933].

Modos de homem \& modas de mulher. Rio e Janeiro: Record, 1986.

HOLANDA, S. Raízes do Brasil. São Paulo: Companhia das Letras, 1995 [1936].

Visão do Paraíso. São Paulo: Brasiliense, Publifolha, 2000 [1959].

LÉVI-STRAUSS, C. 0 pensamento selvagem. Campinas: Papirus, 2011 [1962].

. 0 campo da antropologia. In: Antropologia estrutural dois. São Paulo: Cosac Naify, 2013 [1960].

MARX, K. 0 capital: crítica da economia política. Rio de Janeiro: Civilização Brasileira, 2008 [1867].

MCCRACKEN, G. Cultura e consumo: novas abordagens ao caráter simbólico dos bens e das atividades de consumo. Rio de Janeiro: Mauad, 2003.

ROCHA, E. Magia e capitalismo: um estudo antropológico da publicidade. Rio de Janeiro: Brasiliense, 1985.

FRID, M; CORBO, W. 0 paraíso do consumo: Émile Zola, a magia e os grandes magazines. Rio de Janeiro: Mauad, 2016.

ROCHE, M. Megaevents and modernity: Olympics and expos in the growth of global culture. Londres: Routledge, 2000. 
RODRIGUES, J. C. Antropologia e comunicação: princípios radicais. Rio de Janeiro: Editora PUC-Rio, 2003.

VERBOORD, M.; BRANDELLERO, A. The globalization of popular music, 1960-2010: a multilevel analysis of music flows. Communication Research, v. 45, n.4, p. 603-627, 2018.

SCHWARCZ, L. Complexo de Zé Carioca: sobre uma certa ordem da mestiçagem e da malandragem. Revista Brasileira de Ciências Sociais. São Paulo, v. 29, n.10, p.17-30, 1995.

SENNETT, R. 0 declínio do homem público. São Paulo: Companhia das Letras, 1988.

SIMMEL, G. The metropolis and mental life. In: SENNETT, R. Classic essays on the culture of cities. Nova Jersey: Prentice Hall, Inc.; Englewood Cliffs, 1969 [1903].

VIANNA, H. 0 mistério do samba. Rio de Janeiro: UFRJ/Jorge Zahar, 1995.

Recebido em 30 de julho de 2018. Aprovado em 06 de dezembro de 2018. 